Journal of Environmental
Ans $: 2525-815 \mathrm{X}$

\title{
Proposta metodológica interdisciplinar como ferramenta para o potencial de conservação de nascentes
}

\section{Interdisciplinary methodological proposal as a tool for potential conservation of springs}

\author{
Lívia Câmara Machado ${ }^{a}$, Vanice Santiago Fragoso Selva ${ }^{a}$, Simone Machado Santos ${ }^{\mathrm{a}}$ \\ a Universidade Federal de Pernambuco-UFPE, Av. Prof. Moraes Rego, n. 1235, Cidade Universitária, Recife, \\ Pernambuco. CEP: 50670-901. E-mail: liviamachado.biologa@gmail.com, vanice.selva@gmail.com, \\ smachados@hotmail.com.
}

\begin{abstract}
A R T I C L E I N F O
Recebido 05 Out 2017

Aceito 27 Dez 2017

Publicado 10 Jan 2018

A B S T R A C T

Considering the problems experienced by inappropriate uses and appropriations of spring areas, negative impacts are visible and make it difficult to conserve these sources, which are important forms of access to water in rural areas. The reality points out some conflicts for the conservation of springs, ranging from the form of use and occupation of the territory to the practices carried out by the community. In this sense, studies aiming to overcome methodological gaps in the field of research, aimed at conservation and recovery actions of springs as a practical tool that allows the participation and support of the community for the adequate use of the springs become relevant. The study proposes methodological adjustments with the insertion of a political approach for the evaluation of the conservation potential of springs used for human supply. The methodological adequacy was elaborated from bibliographical researches and consultations in the databases in the area of environmental sciences, seeking the scientific contribution through directed studies in the methodologies and existent and related investigations to the subject. The proposal strengthens its conservation and recovery actions, subsidizing future actions and recovery projects, respecting the local context and the use of water by users. Thus, it is hoped to contribute to overcoming existing conflicts between conservation and use of natural resources, specifically, of the uses and practices carried out in springs in rural areas.
\end{abstract}

Keywords: Conservation of springs, methodological adequacy, interdisciplinarity.

\section{R E S U M O}

$\overline{\text { Em decorrência dos problemas vivenciados pelos usos e apropriações inadequadas }}$ de áreas de nascentes, impactos negativos são visíveis e dificultam a conservação destas fontes que são importantes formas de acesso à água no meio rural. A realidade aponta alguns conflitos para a conservação de nascentes, que vai desde a forma de uso e ocupação do território até as práticas realizadas pela comunidade. Neste sentido, tornam-se relevantes estudos que tem por finalidade suprir lacunas metodológicas no campo de pesquisa, voltadas para as ações de conservação e recuperação de nascentes como ferramenta prática que permita a participação e apoio da comunidade para o uso adequado das nascentes. $\mathrm{O}$ estudo propõe adequações metodológicas com a inserção de uma abordagem política para a avaliação do potencial de conservação de nascentes utilizadas para o abastecimento humano. A adequação metodológica foi elaborada a partir de pesquisas bibliográficas e consultas nas bases de dados na área de ciências ambientais, buscando o aporte científico através de estudos direcionados nas metodologias e pesquisas existentes e relacionados ao tema. A proposta potencializa as próprias ações de conservação e recuperação, subsidiando futuras ações e projetos de recuperação, respeitando o contexto local e o uso da água por parte dos usuários. Destarte, espera-se contribuir para a superação dos conflitos existentes entre 
conservação e utilização dos recursos naturais, em específico, dos usos e práticas realizadas nas nascentes nos espaços rurais.

Palavras-Chave: Conservação de nascentes, adequação metodológica, interdisciplinaridade.

Introdução

As nascentes são importantes fontes de água para sobrevivência das famílias rurais, tanto em atividades domésticas quanto agrícolas. Estas fontes possuem relevância para o desenvolvimento e dinâmica de áreas de produção agrícola e para o consumo humano. As nascentes são responsáveis pela formação dos rios, que fazem parte das bacias hidrográficas. Considera-se nascente, o afloramento na superfície do solo da água de um lençol freático (Barreto, Ribeiro \& Borba, 2010).

As nascentes, na maioria das vezes, são as únicas fontes naturais que atendem as demandas nos espaços rurais, e, que por sua vez possuem grande importância no desenvolvimento das atividades socioeconômicas (Braga, 2011). As nascentes são recursos essenciais para os assentamentos humanos e espécies terrestres, além de habitats para a biota aquática que contribuem para os processos ecológicos e biodiversidade (Davis et al., 2016). Como fontes contribuidoras, suprem a necessidade dos espaços rurais, principalmente pela ausência de um serviço de abastecimento.

No entanto, observa-se que na prática, devido à sua importância e contribuição, as nascentes e as áreas de seu entorno não são utilizadas corretamente conforme prevê a Lei Federal $\mathrm{n}^{\circ}$ 12.651/2012 (Código Florestal Brasileiro). Há, portanto, nos espaços rurais diferentes formas de usos e conflitos que dificultam a sua proteção e consequentemente coloca em risco a existência deste importante recurso.

Destarte, o estudo de Braga, Silva \& Cavalcanti (2013) aponta que existem meios de conciliar a extração ou exploração com a conservação nestas áreas através da adequação da propriedade rural particular ou pública, visando considerar os usos, as práticas e a participação realizada pelos atores que possuem as nascentes como principal fonte de água para a sua sobrevivência.

Nesse sentido, alguns protocolos metodológicos, nacionais e internacionais, estão disponíveis para a avaliação da conservação das nascentes. Nota-se que as abordagens destas ferramentas são direcionadas às diversas áreas de pesquisas e possuem fragilidades, principalmente pela ausência de um protocolo interdisciplinar.

Diante do exposto, observam-se lacunas existentes no campo metodológico, com ferramentas incapazes de mensurar o envolvimento, a participação, os conflitos e características destas áreas prioritárias para conservação.

Destarte, a motivação para realização da pesquisa justifica-se devido à ausência de um protocolo mais abrangente, que priorize a criação de uma ferramenta com a inserção do foco político para avaliar o potencial das nascentes a partir dos usos, das especificidades e das relações políticas que circundam em torno destas fontes.

Portanto, tornou-se relevante o presente estudo, que trouxe como foco a adequação metodológica com a inserção de uma abordagem política para a avaliação do potencial de conservação de nascentes, com o propósito de contribuir com meios para a priorização das nascentes mais sensíveis para a realização de ações de proteção, intervenção e recuperação destas áreas.

\section{Material e Métodos}

A adequação metodológica foi realizada por meio de pesquisas bibliográficas e consultas em bases de dados na área de ciências ambientais, especificamente na Scopus e ScienceDirect, buscando através de um estudo direcionado, as metodologias e protocolos existentes e relacionados ao tema, com a inclusão de parâmetros de ordem política.

Nesta perspectiva, alguns parâmetros das metodologias nacionais elaboradas e validadas por diversos autores (Pinto, 2003; Valente \& Gomes, 2011; Pereira, 2012; Machado, 2013; Oliveira, 2014; Ribeiro, 2014), serviram como principal aporte científico de análise para a adequação metodológica com a inserção do eixo político.

No estudo foram realizadas adequações, com modificações e inclusões nos relevantes parâmetros de análise das nascentes que são utilizadas para fins de abastecimento humano. $\mathrm{O}$ estudo propõe um agrupamento interdisciplinar com três eixos: o ecológico, socioterritorial e político, indicando a importância do trabalho para as ciências ambientais e para a gestão das áreas de nascentes.

A construção do protocolo prioriza os parâmetros do eixo ecológico e do eixo socioterritorial as ações, os usos e as práticas desenvolvidas no entorno das nascentes.

Nos parâmetros do eixo político estão previstas as análises das nascentes, através da participação, atuação e envolvimento do poder 
público/instituições e dos produtores rurais, construídas a partir de percepções coletadas no levantamento de campo.

\section{Resultados}

As metodologias que abordam conceitualmente as nascentes, tanto do ponto de vista de sua conservação e caracterização, possuem abordagens diversas que são atualmente aplicadas em estudos acadêmicos.

Diante da necessidade de uma abordagem com enfoque interdisciplinar no que se refere às nascentes, a presente pesquisa surge como uma ferramenta de contribuição para a avaliação do potencial de conservação destas fontes, sendo aplicável no desenvolvimento de propostas e projetos, e ainda, para a própria gestão das áreas de nascentes.

Destarte, indica-se neste estudo uma estrutura interdisciplinar inédita, a partir do agrupamento dos parâmetros por eixos, que através de situações serão enquadradas de acordo com as pontuações.

Repensando a interdisciplinaridade técnica como importante fator para a gestão dos recursos hídricos, a presente proposta considera 20 importantes parâmetros, agrupados em três eixos distintos: o ecológico, o socioterritorial e o político (Figura 1).

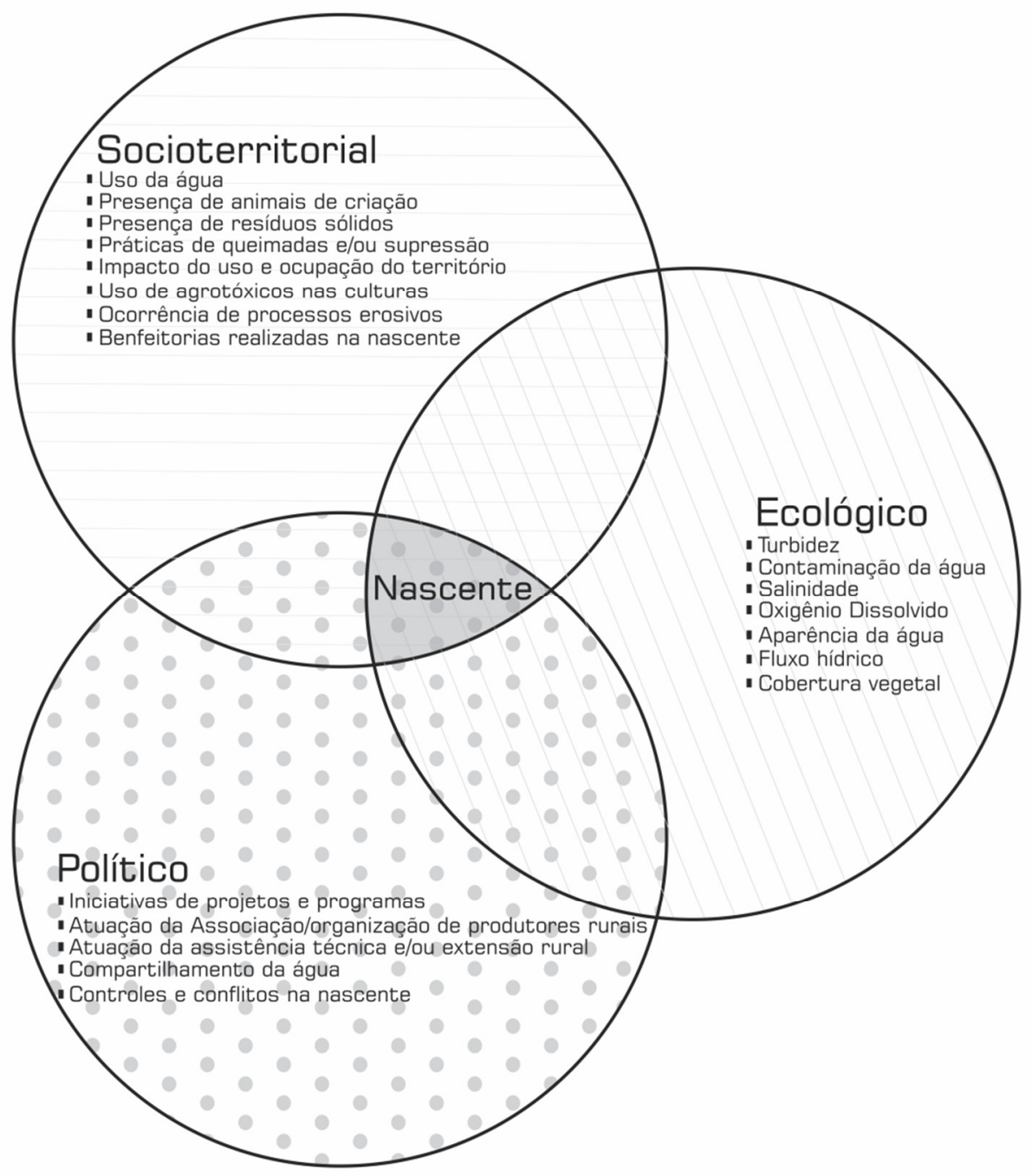

Figura 1. Organização da ferramenta metodológica interdisciplinar para o potencial de conservação de nascentes. Fonte: Elaborado pelos autores (2017).

No eixo ecológico e socioterritorial enquadraram-se parâmetros de Pinto (2003), Valente \& Gomes (2011), Pereira (2012), Machado (2013), Oliveira (2014), Ribeiro (2014), a partir de inclusões e modificações dos autores nesta proposta.
No eixo político, o estudo trouxe uma nova abordagem com parâmetros de ordem política, que influencia diretamente na conservação das nascentes (Quadro 1).

No eixo ecológico, agruparam-se os parâmetros que englobam as relações ecológicas 
presentes nas nascentes e que interferem nos usos e no abastecimento por parte dos usuários, com parâmetros de qualidade da água, de cobertura vegetal e de caracterização da nascente.

No eixo socioterritorial incluiu-se os parâmetros que expressam a relação entre os usuários e as nascentes, do ponto de vista social, bem como das práticas e usos realizados no entorno das nascentes, com parâmetros de uso da água, de práticas realizadas nestas áreas, sejam impactantes ou não ao recurso natural.

Com a inclusão de uma nova abordagem, o eixo político, agruparam-se os parâmetros que apontam os conflitos, o envolvimento e a participação de atores, associações e/ou instituições na tomada política relacionada à conservação de nascentes. Buscou-se neste eixo específico, mensurar o envolvimento político e a atuação pública ou privada para a gestão destas áreas. A partir desta adequação metodológica é sugerida uma ferramenta que priorize as nascentes mais vulneráveis, avaliando a participação e envolvimento político com a inclusão deste eixo.

Nesta proposta, o eixo "Político" incorpora os parâmetros que são essenciais para a conservação das nascentes e que englobam uma série de fatores que contribuem para a conservação destas fontes. Ressalta-se que nenhuma metodologia direcionada a conservação de nascentes, utilizou uma abordagem como esta, que identifica através da participação, possíveis caminhos para uma gestão consolidada do recurso.

Quadro 1. Aporte científico e estrutura metodológica organizada por eixos com inclusão da abordagem política. Fonte: Elaborado pelos autores (2017).

\begin{tabular}{|c|c|c|c|}
\hline \multirow{2}{*}{ Autores } & \multicolumn{3}{|c|}{ Parâmetros } \\
\hline & Eixo Ecológico & Eixo Socioterritorial & Eixo Político \\
\hline Pinto (2003) & Vegetação nativa & - & - \\
\hline Valente e Gomes (2011) & Fluxo hídrico & - & - \\
\hline $\begin{array}{l}\text { Pereira (2012) } \\
\text { Machado (2013) } \\
\text { Oliveira (2014) }\end{array}$ & $\begin{array}{l}\text { Turbidez; Presença de } \\
\text { Escherichia coli; }\end{array}$ & $\begin{array}{c}\text { Presença de resíduos sólidos; } \\
\text { Suspeita de agrotóxico na água; } \\
\text { Uso direto da água; Desproteção } \\
\text { física; Predominância de } \\
\text { cobertura vegetal no solo; } \\
\text { Ocorrência de processos erosivos } \\
\text { no solo; Uso de agrotóxico; } \\
\text { Presença de animais de criação; } \\
\text { Evidência de queimadas ou corte } \\
\text { da vegetação; Ocorrência de } \\
\text { edificações domésticas e/ou } \\
\text { rurais. }\end{array}$ & - \\
\hline Ribeiro (2014) & $\begin{array}{l}\text { Fluxo de água; Cor da água; } \\
\text { Odor da água; Salinidade } \\
(\% o) \text {; Sólidos Dissolvidos } \\
\text { Totais (mg.L-1 }) \text {; Oxigênio } \\
\text { Dissolvido }\left(\mathrm{mg} . \mathrm{L}^{-1}\right) ; \text { Riqueza } \\
\text { da fauna aquática; } \\
\text { Bioindicadores aquáticos; } \\
\text { Cobertura vegetal; Cobertura } \\
\text { do solo; Riqueza da fauna de } \\
\text { invertebrados do solo; } \\
\text { Bioindicadores Terrestres. }\end{array}$ & $\begin{array}{l}\text { Uso da água; Meio captação da } \\
\text { água; Área de inserção; Uso e } \\
\text { ocupação do solo no entorno; } \\
\text { Práticas de manejo sustentável; } \\
\text { Conhecimento local sobre a flora } \\
\text { nativa; Conhecimento local sobre } \\
\text { a fauna nativa; Lançamento de } \\
\text { efluentes domésticos; Ocorrência } \\
\text { de queimadas ou desmatamento; } \\
\text { Ocorrência de processos erosivos; } \\
\text { Presença de animais de criação; } \\
\text { Presença de resíduos sólidos. }\end{array}$ & - \\
\hline Proposta dos autores & 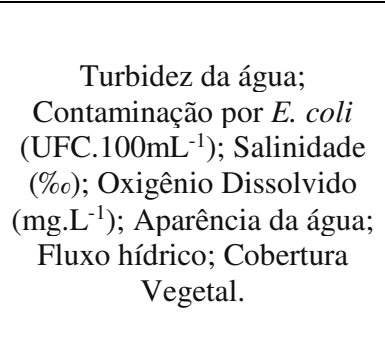 & $\begin{array}{c}\text { Uso da água; Presença de } \\
\text { Animais de criação; Presença de } \\
\text { Resíduos Sólidos; Práticas de } \\
\text { queimadas e/ou supressão da } \\
\text { vegetação; Impacto do uso e } \\
\text { ocupação do território; Uso de } \\
\text { Agrotóxicos nas culturas; } \\
\text { Ocorrências de processos erosivos } \\
\text { no solo; Benfeitorias realizadas } \\
\text { no entorno da nascente. }\end{array}$ & $\begin{array}{c}\text { Iniciativas de Programas e } \\
\text { projetos; Atuação da } \\
\text { Associação/organização de } \\
\text { produtores rurais; Atuação da } \\
\text { assistência técnica e/ou } \\
\text { extensão rural; } \\
\text { Compartilhamento da água; } \\
\text { Controle e conflitos na } \\
\text { nascente. }\end{array}$ \\
\hline
\end{tabular}


Convém ressaltar que para a maioria dos parâmetros da ferramenta considera-se o raio de 50 metros do ponto de afloramento da nascente em alguns dos parâmetros dispostos, conforme prevê a o Novo Código Florestal Brasileiro (Lei Federal $n^{\circ} 12.65 / 2012$ ).

Um aspecto importante é que foram incluídos nove parâmetros, dos 12 abordados na metodologia de Pereira (2012), Machado (2013) e Oliveira (2014), que são: turbidez, presença de Escherichia coli, presença de resíduos sólidos, uso direto da água, presença de cobertura vegetal no entorno, ocorrência de processos erosivos no solo, uso de agrotóxicos, presença de animais de criação e evidência de queimadas ou corte da vegetação, que foram distribuídos no eixo ecológico e no eixo socioterrtorial.

Ressalta-se que os parâmetros de qualidade da água são de extrema importância, visto que a água das nascentes é priorizada para o abastecimento humano, para a subsistência das famílias e desenvolvimento rural dos assentados.

Desta forma, faz-se necessário justificar a exclusão do parâmetro da metodologia validada por Pereira (2012), Machado (2013) e Oliveira (2014), "Suspeita de Agrotóxico na Água", que se tornou redundante, pois a nova proposta não prevê duas situações locacionais de análise, no corpo e no entorno da nascente, conforme a metodologia original dos autores.

Adaptações foram realizadas no parâmetro "Ocorrência de edificações domésticas e/ou rurais", proposto por Pereira (2012),
Machado (2013) e Oliveira (2014) com inclusões realizadas no parâmetro "Uso e ocupação do território", que incorporam as construções e apropriações do espaço no entorno das áreas de nascentes, bem como a preservação da vegetação nativa in loco.

Parâmetros da metodologia de Ribeiro (2014) foram incluídos neste estudo e enquadrados no eixo ecológico, a saber: salinidade, oxigênio dissolvido e cor da água, devido à importância da água para o abastecimento humano e manutenção da vida aquática. Fatores relevantes são as modificações e inclusões realizadas no parâmetro "Desproteção física" de Pereira (2012), Machado (2013) e Oliveira (2014), que foi renomeado na adequação para "Benfeitorias realizadas na nascente".

No parâmetro "Benfeitorias realizadas na nascente" acrescentam-se as atividades de plantação de mudas e cercamento da área da nascente como benfeitorias participativas e adotadas pelos usuários para a conservação das nascentes, além dos aspectos de proteção física, como: a construção de estruturas de alvenaria, anéis e tampas de concreto e instalações hidráulicas, que protegem a nascente.

No eixo ecológico, utilizamos os seguintes parâmetros: (a) Turbidez da água; (b) Contaminação por E. coli (UFC/100mL), (c) Salinidade (\%o), (d) Oxigênio Dissolvido (mg/L), (e) Aparência da água, (f) Fluxo hídrico e (g) Cobertura Vegetal (Quadro 2).

Quadro 2. Descrição e pontuação dos parâmetros do eixo ecológico da metodologia interdisciplinar para o potencial de conservação de nascentes. Fonte: Elaborado pelos autores (2017).

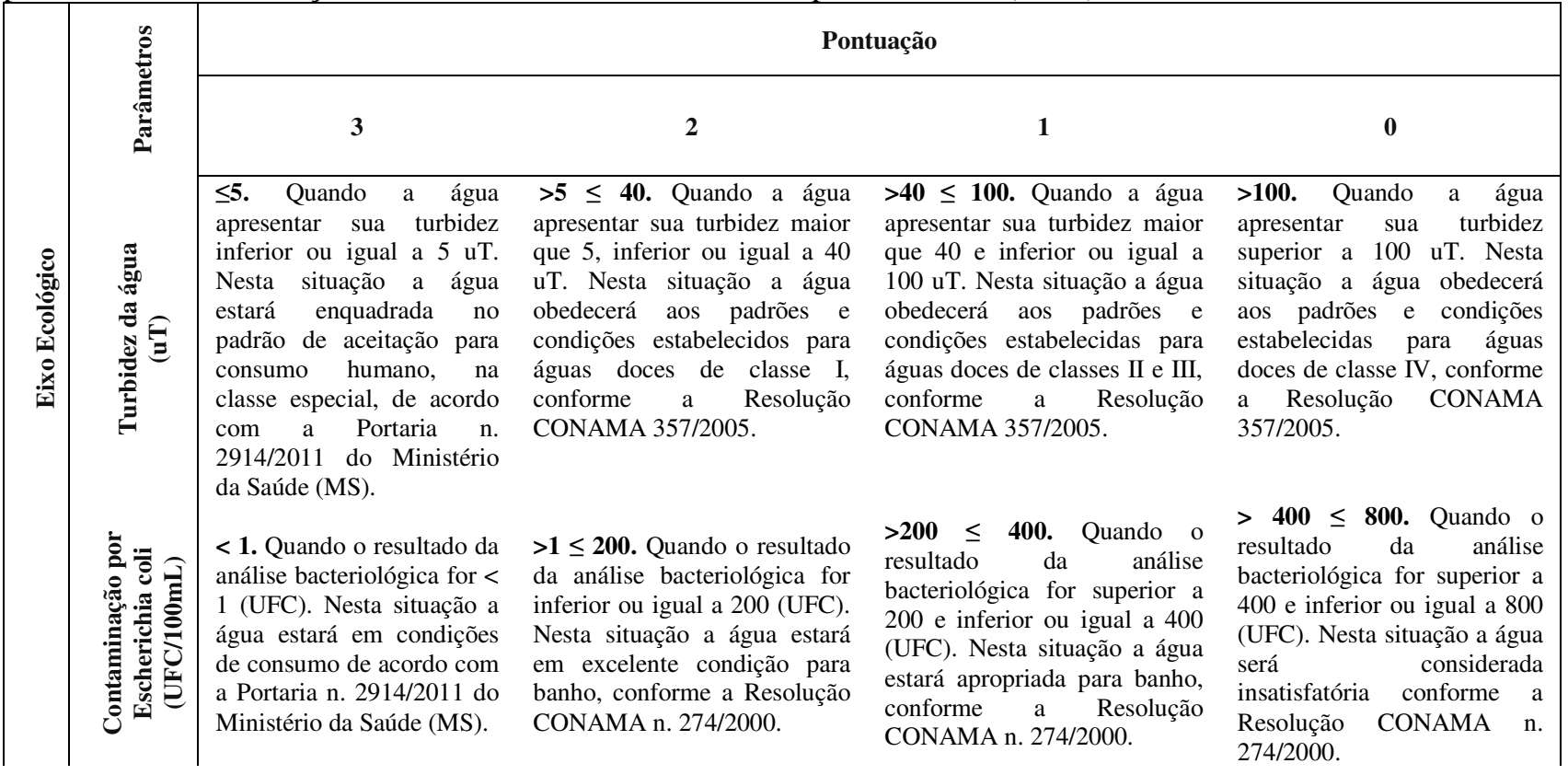




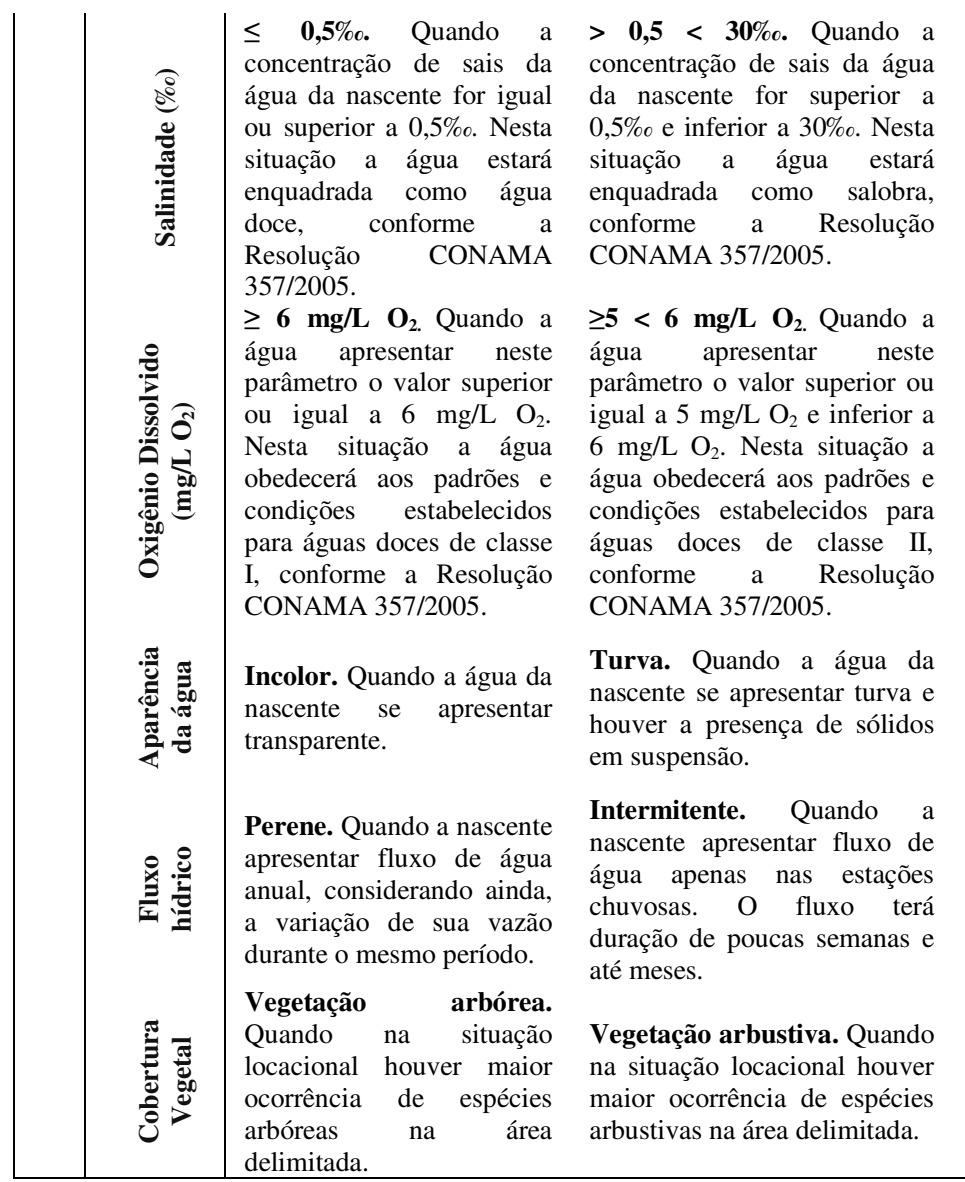
\begin{tabular}{llr}
$\geq$ & $\mathbf{3 0} \%$. & \multicolumn{2}{c}{ Quando a } \\
concentração de sais da água \\
da nascente & for igual ou \\
superior a & $30 \%$. Nesta \\
situação a água & estará \\
enquadrada como salina, \\
conforme a Resolução \\
CONAMA & 357/2005.
\end{tabular}

$\geq 4<5 \mathrm{mg} / \mathrm{L} \mathrm{O}$. Quando a água apresentar neste parâmetro o valor superior ou igual a $4 \mathrm{mg} / \mathrm{L} \mathrm{O} \mathrm{O}_{2}$ e inferior que $5 \mathrm{mg} / \mathrm{L} \mathrm{O}_{2}$. Nesta situação a água obedecerá aos padrões e condições estabelecidos para águas doces de classe III, conforme a Resolução CONAMA 357/2005.

Escura. Quando a água da nascente se apresentar na cor escura.

Efêmero. Quando a nascente apresentar fluxo de água especialmente durante a ocorrência de precipitações. O fluxo terá duração de poucos dias e horas.

Pasto e agricultura de ciclo longo. Quando na situação locacional houver maior ocorrência de pasto ou agricultura de ciclo longo na área delimitada.
Não observado. Quando não houver condições para observação e análise da situação devido à ausência de água na nascente.

Não observado. Quando não houver condições para observação e análise da situação devido à ausência de água na nascente.

Não observado. Quando não houver condições para observação e análise da situação devido à ausência de água na nascente.

Não observado. Quando não houver condições para observação e análise da situação devido à ausência de água na nascente.

Agricultura de ciclo curto. Quando na situação locacional existir na área delimitada a ocorrência de agricultura de ciclo curto.
Considerando os usos e as práticas cotidianas realizadas no entorno e na própria nascente, o eixo "Socioterritorial" inclui os parâmetros que estão diretamente vinculados a estas práticas e se referem aos usos e as ações que de fato são impactantes ou não para manutenção destas fontes (Quadro 3).
Neste eixo, podemos incluir: (h) Uso da água; (i) Presença de animais de criação; (j) Presença de resíduos sólidos; (k) Práticas de queimadas e/ou supressão da vegetação; (l) Impacto do uso e ocupação do solo; (m) Uso de agrotóxicos nas culturas; (n) Ocorrências de processos erosivos no solo; e (o) Benfeitorias realizadas na nascente.

Quadro 3. Descrição e pontuação dos parâmetros do eixo socioterritorial da metodologia interdisciplinar para o potencial de conservação de nascentes. Fonte: Elaborado pelos autores (2017).

\begin{tabular}{|c|c|c|c|c|c|}
\hline \multirow{4}{*}{ 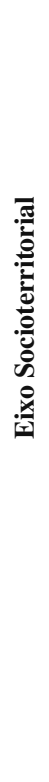 } & \multirow{2}{*}{ 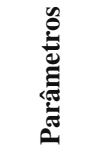 } & \multicolumn{4}{|c|}{ Pontuação } \\
\hline & & 3 & 2 & 1 & $\mathbf{0}$ \\
\hline & 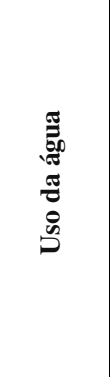 & $\begin{array}{l}\text { Ausente. Quando a } \\
\text { nascente não for utilizada } \\
\text { pela comunidade e usuários } \\
\text { em suas atividades diárias. }\end{array}$ & $\begin{array}{l}\text { Eventual. Quando a } \\
\text { nascente não for utilizada } \\
\text { diariamente pela comunidade } \\
\text { nas atividades como: } \\
\text { consumo humano, lavagens } \\
\text { de roupa e pratos, de forma } \\
\text { que a intensidade da } \\
\text { captação da água não } \\
\text { interfira na disponibilidade } \\
\text { da mesma. }\end{array}$ & $\begin{array}{l}\text { Moderado. Quando a } \\
\text { nascente for utilizada } \\
\text { diariamente pela comunidade } \\
\text { nas atividades como: } \\
\text { consumo humano, lavagens } \\
\text { de roupa e pratos, de forma } \\
\text { que a intensidade da captação } \\
\text { da água interfira na } \\
\text { disponibilidade da mesma. }\end{array}$ & $\begin{array}{l}\text { Elevado. Quando a nascente } \\
\text { for utilizada diariamente pela } \\
\text { comunidade em diversas } \\
\text { atividades, tais como: } \\
\text { consumo humano, lavagens de } \\
\text { roupa, pratos, dessedentação } \\
\text { de animais de criação, } \\
\text { irrigação de culturas, entre } \\
\text { outras, de forma que a } \\
\text { intensidade da captação da } \\
\text { água comprometa a } \\
\text { disponibilidade da mesma. }\end{array}$ \\
\hline & 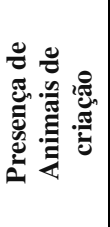 & $\begin{array}{l}\text { Ausente. Quando não se } \\
\text { observar evidências e/ou } \\
\text { presença de animais de } \\
\text { criação na área delimitada } \\
\text { da nascente. }\end{array}$ & $\begin{array}{l}\text { Eventual. Quando se } \\
\text { observar poucas evidências } \\
\text { e/ou vestígios de animais de } \\
\text { criação que corresponda a } \\
\text { uma área com até } 0,5 \mathrm{~m}^{2} \text { da } \\
\text { área delimitada da nascente. }\end{array}$ & $\begin{array}{l}\text { Moderado. Quando se } \\
\text { observar maiores evidências } \\
\text { e/ou presença de animais de } \\
\text { criação que corresponda a } \\
\text { uma área superior a } 0,5 \mathrm{~m}^{2} \mathrm{e} \\
\text { inferior ou igual a } 1 \mathrm{~m}^{2} \mathrm{da} \\
\text { área delimitada da nascente. }\end{array}$ & $\begin{array}{l}\text { Elevado. Quando for } \\
\text { frequente a presença } \mathrm{e} \\
\text { quantidade de vestígios de } \\
\text { animais de criação que } \\
\text { corresponda uma área superior } \\
\text { a } 1 \mathrm{~m}^{2} \text { da área delimitada da } \\
\text { nascente. }\end{array}$ \\
\hline
\end{tabular}




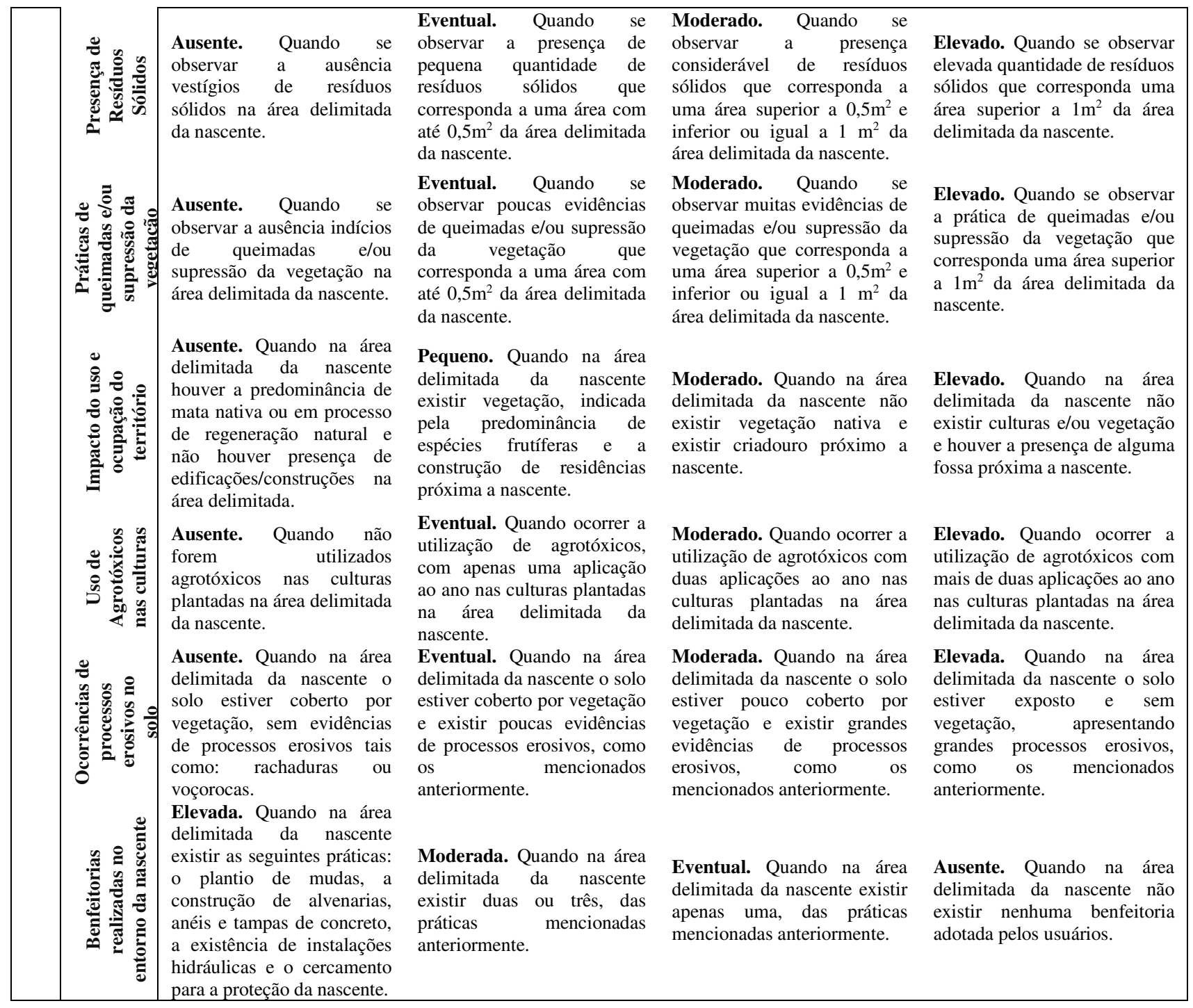

Para ampliar a possibilidade de conservação e recuperação de nascentes, parte-se da ideia de que a inclusão de um eixo político aponte um resultado mais eficaz para a indicação do potencial de conservação de nascentes.

No eixo político (Quadro 4) ressaltamos os parâmetros: (p) Iniciativas de programas e projetos, com foco na atuação de intervenções para melhoria e conservação das nascentes; (q) Atuação da associação/organização de produtores rurais, com a finalidade de mensurar a atuação da comunidade na conservação das nascentes; (r) Atuação da assistência técnica e/ou extensão rural, com foco na atuação da assistência técnica, para suporte e preparação do agricultor para as práticas de conservação das nascentes;

Compartilhamento da água, com a finalidade de mensurar o uso compartilhado das nascentes e sua capacidade de suprir os usos; e, (t) Controle e conflitos na nascente, com foco nas proibições e restrições de acesso a água das nascentes, enquadrados como conflitos de uso da água.

Em suma, a adequação metodológica dispõe 20 parâmetros distribuídos por eixos, justificando a sua importância interdisciplinar e o embasamento científico para a sua inclusão no estudo devido à importância da participação da sociedade na gestão dos recursos ambientais. Os parâmetros apresentados possuem situações distintas com intervalos de notas de 0 a 3 pontos, para cada parâmetro.

Para a indicação do potencial de conservação das nascentes faz-se necessário o somatório da pontuação dos 20 parâmetros para posterior enquadramento, como: elevado, adequado, intermediário, reduzido e crítico.

A nascente com melhor status de conservação deverá alcançar a pontuação máxima no intervalo de 60 a 49 pontos, mostrando-se em nível elevado de conservação; na situação "adequada", a nascente deverá alcançar a pontuação de 48 a 37 pontos, mostrando-se dentro de uma faixa de intervalo adequada e, portanto, ainda considerada conservada.

Na situação intermediária, os intervalos de enquadramento da nascente encontram-se entre 36 a 25 pontos, apontando que a nascente atingiu na escala uma posição mediana, ou seja, neutra. 
Quadro 4. Descrição e pontuação dos parâmetros do eixo político da metodologia interdisciplinar para o potencial de conservação de nascentes. Fonte: Elaborado pelos autores (2017).

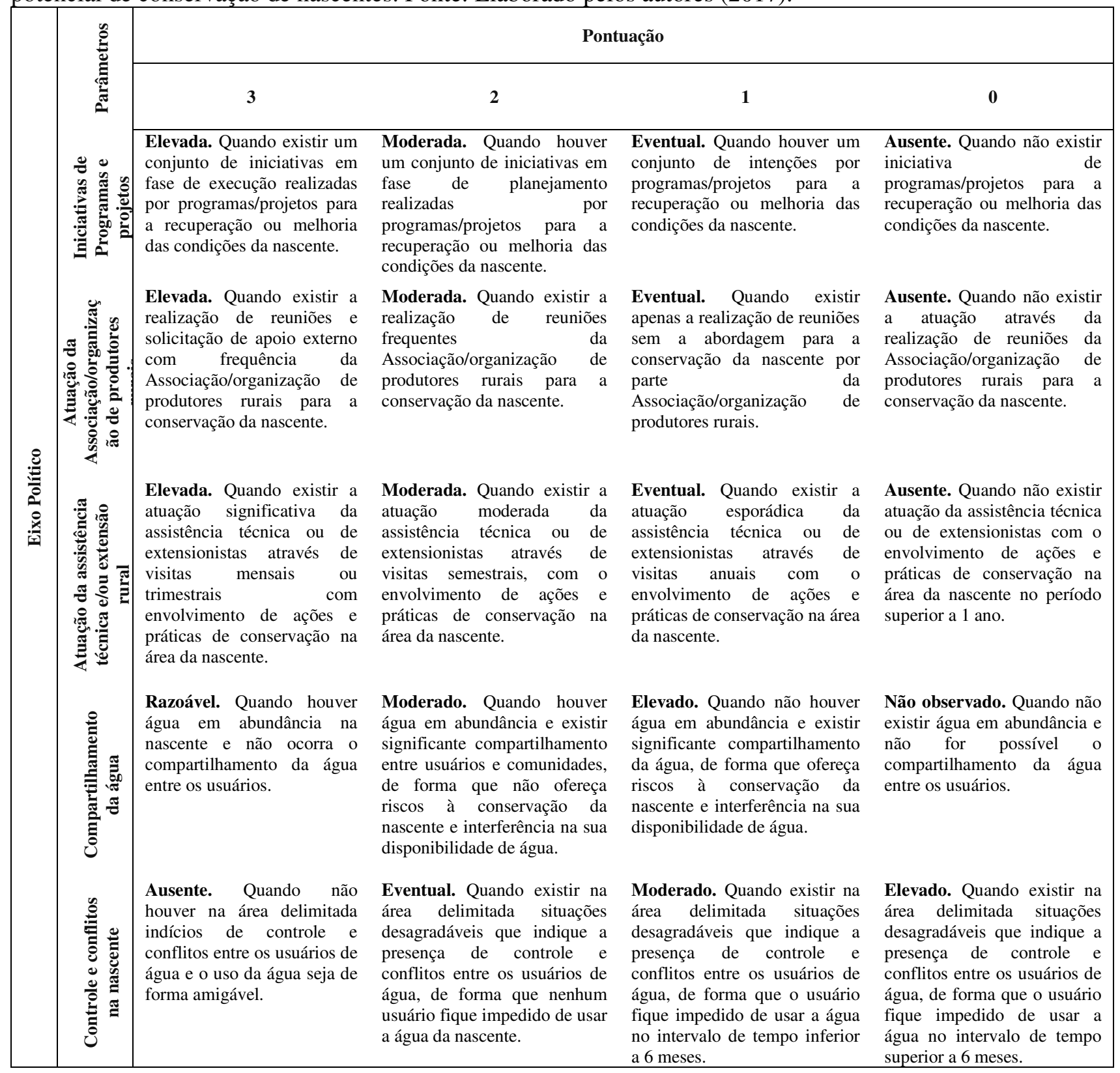

A nascente com o potencial de conservação reduzido estará enquadrada nos intervalos de 24 a 13 pontos, restando o nível mais crítico de conservação da nascente nos intervalos de pontuação de 12 a 0 , considerado estado de alerta da nascente.

\section{Discussão}

Os parâmetros de Turbidez são justificados pela importância da penetração da luz neste meio, pois é através da luz que a fotossíntese pode ser realizada e este fator é essencial por permitir a sobrevivência do meio biótico (Braga, 2005). Com a presença de sólidos suspensos na água há interferências na entrada de luz (reflexão) que consequentemente compromete a realização da fotossíntese.
A presença de material em suspensão, como, por exemplo, partículas minerais e algas, afeta diretamente a turbidez, que por sua vez dificulta, e até mesmo impede, a penetração de luz na água (Pereira, 2012).

Os valores de turbidez da água devem obedecer aos padrões e condições estabelecidos para as classes de água, que são aceitáveis para o consumo humano, como também para outras atividades previstas na Resolução Conama ${ }^{\circ} 357$, de 17 de março de 2005, e, ainda, na Portaria do Ministério da Saúde ${ }^{\circ}$ 2914, de 12 de dezembro de 2011. Para a turbidez são considerados os intervalos $\leq 5,>5 \leq 40,>40 \leq 100$ e $>100$ uT.

$\mathrm{O}$ oxigênio dissolvido é considerado um dos constituintes mais importantes dos recursos hídricos, pois atua como um importante indicador 
de qualidade da água devido a sua relação direta com os tipos de organismos que podem sobreviver em um corpo d'água. A sua ausência denota a presença de poluição de origem orgânica e, em tal ambiente só sobrevivem os organismos anaeróbios.

A presença de sais dissolvidos na água também pode conferir à água sabor salino e características incrustantes, o que justifica a presença destes dois parâmetros devido à importância do uso das nascentes para o atendimento às demandas de consumo humano, tais como: a ingestão, a higiene e a preparação de alimentos (Braga, 2005).

Considerando a Resolução Conama $\mathrm{n}^{\circ}$ 357/2005, os valores para os parâmetros "Oxigênio dissolvido" e "Salinidade", devem se enquadrar nos padrões e condições estabelecidos na referida norma. Nesse sentido, a resolução serviu de base para a criação de uma escala de avaliação que permitisse atribuir notas aos dois parâmetros mencionados neste eixo.

Os valores apresentados nas medições dos parâmetros "Salinidade" e "Oxigênio dissolvido" das nascentes avaliadas permitem que a água seja enquadrada em situações. Com relação à salinidade, como doce $(\leq 0,5 \%)$, no segundo, como salobra $(>5 \%<30 \%)$, no terceiro, como salina ( $\geq 30 \%)$ e, por último, não observada. Na situação "não observada", não haverá condições para observação e análise da situação devido à ausência de água na nascente.

Com relação ao oxigênio dissolvido, nos intervalos: $\geq 6$ mg. $\mathrm{L}^{-1} \mathrm{O}_{2} ; \geq 5<6 \mathrm{mg} . \mathrm{L}^{-1} \mathrm{O}_{2} ; \geq 4<5$ mg.L $\mathrm{L}^{-1} \mathrm{O}_{2}$; e, não observada; na última situação, a ausência de água na nascente, o que impede as análises in loco e o seu enquadramento.

No parâmetro "Aparência da água", a água analisada é enquadrada nos seguintes aspectos: incolor, turva, escura e não observada. Nesta última situação, a ausência de água na nascente impede as observações in loco, bem como o seu enquadramento.

O parâmetro "Contaminação da água por E. coli" também é considerado um importante critério de análise, devido ao principal uso das nascentes nos espaços rurais, que são destinadas, prioritariamente, para a ingestão humana e consumo doméstico. A contaminação da água por micro-organismos patogênicos pode ocasionar doenças de veiculação hídrica, que por sua vez podem causar incapacitação temporária ou até mesmo a morte em seus usuários.

Para o enquadramento e avaliação deste parâmetro, consideramos a Portaria do MS, $\mathrm{n}^{\circ}$
2914 de 12 de dezembro de 2011, que dispõe sobre os procedimentos de controle e de vigilância da qualidade da água para consumo humano e seu padrão de potabilidade, e ainda, a Resolução Conama, $\mathrm{n}^{\circ} 274$, de 29 de novembro de 2000 , que revisa os critérios de balneabilidade. Os valores encontrados nas nascentes são enquadrados nos padrões de potabilidade e balneabilidade, ambos, indicando a água como satisfatória para as distintas atividades de abastecimento humano previstas no uso das nascentes.

Os valores apresentados na medição do parâmetro "Contaminação da água por E. coli" nas nascentes permite que a água seja enquadrada em quatro situações: $<1$; $>1 \leq 200$; $>200 \leq 400$; e, $>400 \mathrm{UFC} / 100 \mathrm{~mL}$. O primeiro intervalo será enquadrado nos padrões de potabilidade da referida Portaria, sendo os três últimos intervalos enquadrados nos padrões de balneabilidade de acordo com a Resolução Conama $n^{\circ}$ 274/2000. Nas nascentes rurais além da ingestão da água há também o contato secundário, realizado atráves do banho.

Considerando o parâmetro "Cobertura vegetal", busca-se indicar qual o tipo de vegetação o entorno da nascente apresenta, permitindo ainda relacioná-lo diretamente com as atividades antrópicas realizadas na área pela comunidade, como a exemplo, a prática da agricultura de ciclo longo e curto. Ressalta-se que a melhor pontuação deste parâmetro ocorre devido a uma maior quantidade de espécies arbóreas na sua área delimitada, no raio de 50 metros do ponto de afloramento da nascente.

O parâmetro cobertura vegetal considera o previsto na Resolução Conama ${ }^{\circ} 303$, de 20 de março de 2002, que, em seu Art. $3^{\circ}$, inciso II, determina que as APP's são áreas protegidas, cobertas ou não por vegetação nativa e que a ela incumbe-se a função ambiental de preservar os recursos hídricos, a paisagem, a estabilidade geológica e a biodiversidade. Também são áreas que facilitam o fluxo gênico de fauna e flora, protegem o solo e são capazes de assegurar o bem-estar das populações (Brasil, 2012).

Estudos realizados por Silva et al. (2017) apontaram o conflito do uso e da ocupação do solo nas Áreas de Proteção Permanente-APP's, evidenciando a presença do pasto como principal atividade antrópica nas áreas legalmente protegidas. Resende et al. (2009), no que se refere à presença de vegetação no entorno das nascentes, apontaram um bom estado de preservação das 
fontes que possuíam a presença de vegetação na APP com área igual ou superior a 50 metros de cobertura vegetal.

Para o parâmetro "cobertura vegetal" são consideradas quatro situações. A primeira, quando houver maior existência de espécies arbóreas no seu entorno, a segunda, quando a maior ocorrência for de espécies arbustivas, a terceira, quando na situação locacional a predominância for pasto ou agricultura de ciclo longo e, na última situação, quando existir maior ocorrência da prática de agricultura de ciclo curto no seu entorno.

Ainda no eixo ecológico, ressaltamos a importância do último parâmetro "Fluxo Hídrico", apontado no conceito de Valente \& Gomes (2011). Os autores classificam as nascentes dos cursos de água de acordo com a sua vazão, na persistência de seus fluxos, como: perene, intermitente, temporária ou efêmera. O fluxo da água é levado em consideração, tendo em vista a sua importante relação com os usos e as práticas que são desenvolvidas pelas comunidades, que se apropriam das nascentes como principal fonte de água nestes espaços.

No parâmetro "Fluxo Hídrico", os intervalos utilizados são: perene, intermitente, temporário ou efêmero e não observado. Perene, quando a nascente se manifestar o ano todo, mesmo com variações de vazão; intermitente, quando a nascente possuir vazão no período chuvoso, secando apenas na estação seca; temporário ou efêmero, quando a nascente apresentar vazão somente com resposta direta à precipitação, por poucas horas; e na última situação quando não houver condições para observação direta e análise da situação in loco.

Pinto et al. (2004) mencionaram a extrema importância do uso adequado da terra e de práticas de conservação dos solos nestas áreas, para que possa permitir a interceptação da água da chuva, reduzir a quantidade e a velocidade do escoamento superficial e aumentar a sua infiltração, possibilitando assim a recarga do lençol freático que é responsável pela alimentação das nascentes e consequentemente por sua vazão.

De acordo com a disponibilidade de água presente nas nascentes, faz-se necessário avaliar o uso direto da água pela comunidade, considerando a intensidade do uso e sua captação, e ainda, quais as atividades que demandam em maior quantidade o uso da água da nascente. Neste parâmetro, os usos da água não devem comprometer a sua disponibilidade.

Dentre as situações que podemos verificar in loco no parâmetro "Uso da água", a nascente poderá ser enquadrada nos intervalos: ausente, eventual, moderado e elevado.

O uso ausente indica a não utilização da nascente pela comunidade/usuários; o uso eventual quando a nascente não for utilizada diariamente pelos usuários nas atividades relacionadas ao consumo humano, por exemplo, na lavagem de pratos e/ou roupas de forma que a captação não interfira na disponibilidade da água.

No uso moderado quando for utilizada diariamente pelos usuários nas atividades relacionadas ao consumo humano, de forma que a captação interfira na disponibilidade de água da nascente; e no elevado, quando a nascente for utilizada diariamente nas atividades de consumo humano, em lavagens de roupa e/ou pratos, e ainda, na dessedentação de animais de criação, na irrigação de culturas, entre outras atividades, de forma que a intensidade da captação da água comprometa diretamente a disponibilidade hídrica e vazão da nascente.

Os parâmetros "Presença de animais de criação", "Presença de resíduos sólidos" e "Uso de agrotóxicos nas culturas" são de extrema importância visto que refletem as práticas impactantes desenvolvidas no meio rural e que podem interferir diretamente na conservação das nascentes, resultando em um processo de poluição e comprometimento dos corpos d'água. Nesse sentido, Pinto et al. (2004) constataram em seu estudo que as principais perturbações encontradas nas nascentes foram: compactação do solo pelo gado e pelas práticas de preparo para o plantio de culturas agrícolas, presença de lixo, estrume, erosão, grandes voçorocas e desmatamento.

Resende et al. (2009) também identificaram que os principais fatores de perturbação em APP's são: (a) presença de animais, (b) escoamento superficial de sedimentos e resíduos oriundos das atividades agropecuárias no entorno das nascentes, (c) presença de resíduos sólidos como garrafas plásticas, latas e vasilhames de insumos agrícolas, (d) desmatamento, (e) presença de plantas invasoras, (f) queimadas e (g) intervenção antrópica na nascente, como exemplo, o desvio do curso de água para irrigação e uso de APP para plantações.

Desta forma, o pisoteio de animais e seus dejetos, bem como o descarte inadequado de resíduos e substâncias nocivas à saúde podem contaminar a água da nascente e trazer riscos as pessoas que possuem estas fontes como principal meio de abastecimento. Palivoda \& Povaluk (2015) encontraram, nas nascentes na área rural do município de Itaiópolis no Estado de Santa Catarina, valores altos de coliformes totais devido à presença de gado no entorno destas áreas, o que 
indica que os dejetos são infiltrados no solo e, consequentemente, no lençol subterrâneo resultando na contaminação das nascentes.

Sobre esse aspecto, no parâmetro "Presença de animais de criação", os intervalos utilizados para a análise da situação in loco são: ausente, eventual, moderado e elevado.

No intervalo ausente, quando não se observar evidências e/ou presença de animais de criação; no eventual, quando na área delimitada se observar poucas evidências e/ou presença de animais de criação com até $0,5 \mathrm{~m}^{2}$ da área delimitada; no moderado, quando se observar maiores evidências e/ou frequente presença de animais de criação $\left(>0,5 \leq 1 \mathrm{~m}^{2}\right)$ da área delimitada; e no elevado, quando além da presença frequente de animais houver grande quantidade de vestígios acima de $1 \mathrm{~m}^{2}$ da área delimitada da nascente.

Para o parâmetro "Presença de resíduos sólidos" são intervalos de análise: ausente, eventual, moderado e elevado. No intervalo ausente, quando não existir presença de resíduos na área delimitada da nascente; no eventual, quando se observar a presença de pequena quantidade de resíduos sólidos com até $0,5 \mathrm{~m}^{2}$ na área; o moderado, quando for considerável a presença de resíduos na área $\left(>0,5 \leq 1 \mathrm{~m}^{2}\right)$; e elevado, quando se observar grande quantidade de resíduos sólidos na área, ultrapassando $1 \mathrm{~m}^{2} \mathrm{da}$ área delimitada da nascente.

No parâmetro "Uso de agrotóxicos nas culturas", são critérios de observação as seguintes situações: ausente, eventual, moderado e elevado. No ausente, quando não existir o uso de agrotóxicos; no eventual quando se constatar o uso de agrotóxicos com uma única aplicação ao ano nas culturas plantadas na área delimitada da nascente; no moderado, quando se constatar o uso de agrotóxicos com duas aplicações ao ano; e no elevado, quando o uso ultrapassar três aplicações ao ano nas culturas plantadas na área delimitada da nascente.

Com relação ao uso de substâncias nocivas nas práticas utilizadas no entorno de nascentes, Laini et al. (2012) realizaram um estudo sobre a contaminação e a dispersão de herbicidas em nascentes de planícies, indicando que a contaminação por herbicidas é considerada uma séria ameaça aos ecossistemas que dependem da água subterrânea. No estudo os autores indicam que a gestão a as práticas agrícolas adequadas são benéficas e reduziriam a contaminação das fontes. Nesse sentido, Krutz et al. (2005) e Borin et al. (2010) indicam o uso de tiras ripícolas como medida benéfica para prevenir escoamento superficial, o derrame de pulverização e o fluxo de contaminantes subterrâneos.

Entende-se que os processos erosivos são eventos naturais que podem ser intensificados pela ação humana na medida em que são realizados usos inadequados do solo e práticas nocivas ao meio ambiente. Convém ressaltar também sobre a importância da vegetação ciliar para as nascentes, visto que a redução da mesma oferece grandes consequências ao ambiente, dentre elas: o aumento relevante dos processos de erosão nos solos, redução da biodiversidade e ainda prejuízos na hidrologia local.

O parâmetro "ocorrência de processos erosivos no solo" possui os seguintes critérios de observação: ausente, eventual, moderado elevado. $\mathrm{O}$ ausente, quando na área delimitada da nascente não existir evidências de processos erosivos e o solo estiver coberto por vegetação; o eventual, quando o solo existir presença de vegetação e poucas evidências de processos erosivos tais como: rachaduras ou voçorocas; o moderado, quando na área delimitada o solo estiver pouco coberto por vegetação e existir grandes evidências de processos erosivos, corforme mencionado anteriormente; e elevado, quando o solo estiver totalmente exposto com a existência de grandes processos erosivos corforme mencionado anteriormente na área delimitada da nascente.

Balbinot et al. (2008) trataram da dinâmica das nascentes e do lençol freático, que pode ser modificada conforme a utilização de práticas e diferentes formas de manejo da vegetação no entorno destas fontes. Sob este aspecto, os autores indicam que a redução da cobertura vegetal contribui para a diminuição da infiltração da água no solo e influencia no aumento da vazão de escoamento (formação de enxurradas), o que podem reduzir a vazão das nascentes ou, até mesmo, comprometer a existência das mesmas. $\mathrm{O}$ estudo aponta a importância da presença de vegetação no entorno da nascente para facilitar o processo de infiltração da água nos lençóis freáticos e, consequentemente, para que ocorra o aumento da disponibilidade hídrica da nascente.

Pereira (2012) afirma que o controle da quantidade e qualidade dos recursos hídricos depende do disciplinamento do uso e ocupação do solo na bacia hidrográfica. Sobre este aspecto, a autora afirma que este disciplinamento deve ser feito de modo a provocar alterações compatíveis com os mananciais, levando em consideração a função dos seus usos, pois, o ciclo hidrológico e a gênese dos corpos d'água podem ser afetados severamente.

Considerando o "Impacto do uso e ocupação do solo", Mendonça (2000) afirma 
sobre a forte relação entre a degradação paulatina de APP's aos eventos como: o parcelamento de determinada área; os consequentes processos de retirada da vegetação; a impermeabilização do solo e as ações antrópicas promovidas por moradores. Pinto et al. (2004) indicaram que a ocupação das áreas de recarga com pastagem, cultivo agrícola e café é um forte indício para o aumento de nascentes perturbadas e degradadas.

Rossi et al. (2015) realizaram um estudo sobre as interferências geológicas na qualidade da água de nascentes boreais, apontando nos resultados indícios da prática de agricultura em pequena escala na água das nascentes como fator de comprometimento da água.

Considerando o parâmetro "Impacto do uso e ocupação do solo", as situações observadas in loco são: ausente, pequeno, moderado e elevado. No ausente, na área delimitada deve predominar a mata nativa ou em processo de regeneração natural; no pequeno, na área delimitada quando existir a predominância de diversas culturas e/ou espécies frutíferas e a construção de residências próxima a nascente; no moderado, quando na área delimitada não existir vegetação nativa e existir criadouro próximo a nascente; e no elevado, quando não existir culturas e/ou vegetação e houver a presença de alguma fossa séptica próxima a nascente.

Com relação às práticas de queimadas e/ou supressão da vegetação, a nascente poderá ser enquadrada nos intervalos: ausente, eventual, moderado e elevado.

No intervalo ausente, quando se observar a ausência de queimadas e/ou supressão da vegetação na área delimitada da nascente; no eventual, se observar poucas evidências de queimadas e/ou supressão da vegetação que corresponda a uma área com até $0,5 \mathrm{~m}^{2}$ da área delimitada da nascente.

No intervalo moderado, quando se observar muitas evidências de queimadas e/ou supressão da vegetação que corresponda a uma área maior do que $0,5 \mathrm{~m}^{2}$ e menor ou igual a $1 \mathrm{~m}^{2}$ da área delimitada da nascente; e no elevado, se observar a prática de queimadas e/ou supressão da vegetação que corresponda uma área maior do que $1 \mathrm{~m}^{2}$ da área delimitada da nascente.

Destarte, os parâmetros como a presença de animais de criação, de resíduos sólidos, de queimadas e/ou supressão da vegetação, de processos erosivos no solo, e ainda, de agrotóxicos nas nascentes são fatores de grande importância na verificação dos impactos que são ocasionados pelos usos, práticas e apropriações destas áreas pela comunidade. O desmatamento destas áreas representa a perda de uma diversidade biológica insubstituível, uma séria ameaça à existência das nascentes e, consequentemente, dos cursos de água que delas dependem (Resende et al., 2009).

Considerando o parâmetro "Benfeitorias realizadas na nascente", indicamos as possíveis práticas benéficas às nascentes que são realizadas e adotadas pela comunidade que utiliza o recurso. De acordo com este parâmetro, são consideradas benfeitorias: (a) construção de alvenarias, anéis e tampas de concreto, (b) existência de instalações hidráulicas, (c) cercamento para proteção da nascente, e (d) plantio de mudas em seu entorno.

Sobre o plantio no entorno das nascentes, Rodrigues \& Gandolfi (2000) afirmam que, para a recuperação de áreas totalmente degradadas, sugere-se a implantação de consórcios de diferentes espécies arbóreas introduzidas na área através do plantio alternado ou de combinações de espécies.

Sendo assim, as iniciativas como proteger a nascente com estruturas de proteção, e ainda, plantar mudas de espécies arbóreas no seu entorno são consideradas como medidas que devem ser incluídas como parâmetro no estudo. Ressalta-se que as nascentes, quando utilizadas pela comunidade, devem-se ter condições adequadas de uso, como exemplo, a instalação de estruturas físicas protetoras, a fim de evitar a contaminação das águas e proliferação de doenças.

Nesse sentido, o parâmetro "Benfeitorias realizadas na nascente", prevê as seguintes situações: elevada, moderada, eventual e ausente.

$\mathrm{Na}$ situação elevada enquadram-se práticas como o plantio de mudas, a construção de alvenarias, anéis e tampas de concreto, a existência de instalações hidráulicas e o cercamento para a proteção da nascente; na moderada, quando existir duas ou três das práticas mencionadas na primeira situação; na eventual, quando apenas existir uma das práticas mencionadas; e ausente, quando na área delimitada não existir nenhuma benfeitoria realizada, indicando descaso e falta de comprometimento com a conservação da nascente por parte dos usuários.

Considerando o parâmetro "Iniciativas de programas e projetos", dispõe das iniciativas por parte do poder público, organizações não governamentais ou instituições privadas, através de projetos ou programas com a finalidade de recuperar ou realizar melhorias nas áreas de nascentes que sofrem ou possam sofrer impactos decorrentes de ações antrópicas.

Dentre as situações descritas, a nascente poderá ser enquadrada nos intervalos: elevado, moderado, eventual e ausente nas ações 
realizadas. No elevado, quando houver um conjunto de iniciativas em fase de execução realizadas por algum programa/projeto em funcionamento para a recuperação das nascentes; o moderado, quando o conjunto de iniciativas estiver em fase de planejamento, sob as mesmas condições mencionadas anteriormente; o eventual, quando houver um conjunto de intenções por parte de programas/projetos; e o ausente, quando não existir nenhuma iniciativa que tenha como objetivo recuperar e conservar as nascentes.

Ressalte-se que a importância de projetos nestas áreas potencializa a atuação da comunidade/usuários para uso adequado das nascentes, seja no estímulo de práticas agroecológicas e na própria conscientização ambiental.

Nesse sentido, Pereira (2012) constatou através do Projeto Nascentes do Natuba, que a qualidade e quantidade de água disponibilizada pelas nascentes podem ser melhoradas desde que sejam adotadas medidas de recuperação, contribuindo desta forma para a sustentabilidade ambiental do assentamento. Dentre as principais atividades realizadas no projeto, pode-se indicar: as ações de conservação da nascente, com o replantio de espécies nativas em seu entorno; e os planos de intervenção física, com a recuperação e proteção de algumas nascentes utilizando estruturas protetoras.

Nesta mesma perspectiva, o projeto Olho D’Água, com início das atividades em 2002, desenvolveu ações de preservação e recuperação de nascentes que abastecem o Rio Tabatinga em Minas Gerais, o qual objetivou a promoção da sustentabilidade de pequenas propriedades rurais no cerrado e conscientização da comunidade. Dentre as principais ações indicadas no projeto, destacam-se a necessidade de intervenções por parte da comunidade e de órgãos públicos, na adoção de medidas mitigadoras dos impactos indicados, tais como: a recomposição de matas ciliares e da prática do manejo sustentável no local (Duarte et al., 2004).

Considera-se, também, na proposta, a importância da atuação da associação/organização e ou cooperativas de produtores, que são, de fato, instituições sociais responsáveis pela consolidação de projetos dentro de assentamentos e que buscam a solução de interesses e melhoria nas condições de vida, tanto nos aspectos sociais, econômicos e políticos, como também ambientais.

Miranda (2011) aponta o potencial das organizações sociais e produtivas, indicando a valorização da participação dos assentados nas decisões coletivas, nos projetos produtivos e de gestão ambiental para o verdadeiro estabelecimento como agricultores familiares em áreas de assentamentos rurais.

Considerando o parâmetro de "Atuação da associação/organização de produtores rurais", serão avaliadas a atuação da associação/organização de produtores locais com relação ao envolvimento e iniciativas para atividades de melhorias e conservação das nascentes. Nesse sentido, as associações e cooperativas são como instrumentos de mediação, interlocução e tradução, que refletem uma forma de organização social, produtiva e de uso dos recursos naturais (Miranda, 2011). No parâmetro indicado, os intervalos adotados são: elevado, moderado, eventual e ausente.

No intervalo elevado, quando existir significativa atuação e envolvimento com relação às iniciativas de melhorias e conservação das nascentes; no moderado, quando for moderada a atuação e envolvimento em prol de melhorias e conservação das nascentes; no eventual, quando a atuação e iniciativas forem esporádicas; e no ausente, quando não existir nenhuma associação/organização de produtores rurais no assentamento.

O parâmetro "Atuação da assistência técnica e/ou extensão rural", responderá sobre todo o acompanhamento e atuação da assistência técnica ou extensionistas com relação às orientações e apoio nas atividades que, de forma direta ou indireta, estão relacionadas às práticas e usos da água das nascentes. Na proposta, entendese que são essenciais o apoio e o estímulo de extensionistas nas práticas ecologicamente viáveis e que considerem os aspectos de proteção e conservação das nascentes.

Considerando o parâmetro "Atuação da assistência técnica e/ou extensão rural" considerase o previsto na Lei $\mathrm{n}^{\circ} 12.188$, de 11 de janeiro de 2010, que institui a Política Nacional de Assistência Técnica e Extensão Rural para a Agricultura Familiar e Reforma AgráriaPNATER, que preconiza a autação da assistência técnica e extensão rural com o suporte às atividades desenvolvidas no campo com a conservação dos recursos naturais.

A Lei $n^{\circ} 12.188 / 2010$ objetiva: a promoção do desenvolvimento rural sustentável, o desenvolvimento de ações voltadas ao uso, manejo, proteção, conservação e recuperação dos recursos naturais, dos agroecossistemas e da biodiversidade e construção de sistemas de produção sustentáveis a partir do conhecimento científico, empírico e tradicional.

Nesse sentido, Silva \& Braga (2010) identificaram desafios com relação à adequação 
ambiental e conservação de nascentes em assentamentos rurais, como: (a) os conflitos entre a conservação e a prática da agricultura familiar; (b) a falta de planejamento na distribuição da terra e orientação de seu uso; (c) a carência de estratégias de sustentabilidade em áreas de assentamento rurais por parte do Instituto Nacional de Colonização e Reforma Agrária INCRA; e d) a ausência de assistência técnica para melhor aproveitamento para fins agropastoris e conservacionistas.

Diante do exposto, torna-se fundamental incluir como parâmetro a atuação da assistência técnica/extensão rural, pois são através de processos educativos não formais que são oferecidos subsídios para as ações de conservação e uso das nascentes.

No parâmetro, "Compartilhamento da água", se objetiva a verificação do uso intenso da água, quando esta for compartilhada com as famílias/comunidade no local.

Estudos realizados por Machado (2013) indicaram que as nascentes que possuíam grande oferta hídrica e qualidade satisfatória de água eram compartilhadas entre diversos usuários das parcelas do Assentamento Caricé, na zona rural da Mata Sul de Pernambuco. Sobre este ponto de vista, o foco do parâmetro é relacionar a oferta hídrica e o compartilhamento da água, de forma que esta prática não ofereça riscos à conservação e não interfira na vazão da nascente.

$\mathrm{Na}$ situação, os riscos de conservação serão observados através dos intervalos: razoável, moderado, elevado e não observado.

No primeiro, quando se observar a disponibilidade de água $e \quad o$ seu não compartilhamento, ou quando existir compartilhamento razoável entre os usuários/comunidade e disponibilidade hídrica em abundância de forma a não oferecer riscos à nascente; no segundo, quando houver água e seu compartilhamento for moderado, de forma que não ofereça também riscos à nascente; no terceiro, quando não houver água em abundância e existir o compartilhamento intenso, de forma que ofereça riscos à conservação da nascente; e no último, quando não existir água suficiente na nascente que permita o seu compartilhamento.

No parâmetro "Controle e conflitos na nascente", ressaltamos a averiguação de possíveis conflitos e controles no uso da água das nascentes que refletem diretamente na sua conservação.

Estudos realizados por Araújo (2012) apontaram os conflitos no uso dos recursos hídricos do reservatório público de Carpina em Pernambuco que refletiam impactos, tanto do ponto de vista ambiental, como social e político.
O estudo constatou as inúmeras práticas de apropriação, as causas imediatas dos conflitos e as consequências destas práticas realizadas pelos usuários da barragem, que são: as empresas privadas, o poder público, os pescadores, os agricultores, os proprietários de terra e a Cooperativa Mista dos Trabalhadores Rurais e Agricultura Familiar de Carpina (COMTRAF).

Sobre este aspecto, Little (2001) indica os conflitos ambientais como disputas entre diversos grupos sociais derivados de diferentes tipologias de relações que são mantidas com o meio natural.

Neste último parâmetro são avaliadas as situações que indiquem a presença de permissões/controle no uso da nascente por parte dos usuários/comunidade local. Os intervalos para análise do parâmetro são: ausente, eventual, moderado e elevado.

No intervalo ausente, na área delimitada não teremos indícios de controle e conflitos entre os usuários de água; no eventual, na área delimitada teremos indícios de controle e conflitos, de forma que não sejam prejudiciais à conservação da nascente; no moderado, quando na área delimitada existirem controles e conflitos de forma esporádica, que sejam prejudiciais à sua conservação; e no elevado, quando existirem conflitos e controles graves que interfiram e prejudiquem diretamente à conservação da nascente.

\section{Conclusão}

A partir da adequação metodológica com inclusões e adaptações de metodologias existentes e com o acréscimo de uma nova abordagem com parâmetros de ordem política, o presente estudo complementa as metodologias existentes e aponta uma nova ferramenta interdisciplinar para a avaliação do potencial de conservação das nascentes, mostrando-se inovadora, principalmente por sua nova abordagem que mensura a partir de eixos, todas as relações existentes nestas áreas, de ordem ecológica, socioterritorial e política.

A metodologia proposta permitirá a indicação do potencial de conservação das nascentes, permitindo a potencialização de ações de conservação e recuperação de nascentes de forma interdisciplinar, com enfoque na participação e envolvimento comunitário, com probabilidade de subsidiar futuras ações e projetos de recuperação, respeitando o contexto local e o uso da água por parte dos usuários.

A presente proposta identifica e preenche lacunas na temática indicada, a exemplo, na abordagem interdisciplinar, que considera a utilização de novos parâmetros para a conservação 
das nascentes, com vistas para o abastecimento humano. Trata-se de uma importante ferramenta para a superação dos conflitos existentes entre conservação e utilização dos recursos naturais, em específico, dos usos e práticas realizadas nas nascentes nos espaços rurais e o fortalecimento de políticas que considerem as especificidades do meio rural.

\section{Agradecimentos}

A primeira autora agradece o apoio financeiro da Coordenação de Aperfeiçoamento de Pessoal de Nível Superior (CAPES), através da concessão de bolsa de estudo, ao Programa de Pós-Graduação em Desenvolvimento e Meio Ambiente da Universidade Federal de Pernambuco (UFPE).

\section{Referências}

ARAÚJO N. C. F. DE. 2012. Conflitos ambientais tendo como objeto o uso da água de reservatório público. Dissertação de Mestrado, Universidade Federal de Pernambuco. Recife, Pernambuco. 139p.

BALBINOT, R.; OLIVEIRA, N. K. DE; VANZETTO, S. C.; PEDROSO, K.; VALERIO, A. F. 2008. O papel da floresta no ciclo hidrológico em bacias hidrográficas. Ambiência Revista do Setor de Ciências Agrárias e Ambientais, v. 4, n. 1. p. 1-19.

BARRETO, S. R.; RIBEIRO, S. A.; BORBA, M. P. 2010. Nascentes do Brasil: estratégias para a proteção de cabeceiras em bacias hidrográficas. WWF-Brasil, São Paulo.

BRAGA, B. et. al. 2005. Introdução à Engenharia Ambiental. Pearson Prentice, São Paulo. 336p.

BRAGA, R. A. P. 2011. As Nascentes como Fonte de Abastecimento de Populações Rurais Difusas. Revista Brasileira de Geografia Física, v. 5, p. 974-985.

BRAGA, R. A. P.; SILVA, C. E. M.; CAVALCANTI, C. A. V. 2013. Guia para adequação ambiental em assentamentos rurais: a partir da experiência em assentamentos rurais da zona da mata de Pernambuco. ANE, Recife.

BRASIL, 2010. Lei $\mathrm{n}^{\circ} 12.188$, de 11 de janeiro.

BRASIL, 2012. Lei ${ }^{\circ} 12.651$, de 25 de maio.

BORIN, M.; PASSONI, M.; THIENE, M.; TEMPESTA, T. 2010. Multiple functions of buffer strips in farming areas. Europ. J. Agronomy, n. 32. p. 103-111.

CONAMA. Conselho Nacional do Meio Ambiente, 2000. Resolução $\mathrm{n}^{\circ}$ 274: critérios de balneabilidade em águas brasileiras Brasília.

CONAMA. Conselho Nacional do Meio Ambiente, 2002. Resolução $n^{\circ}$ 303: parâmetros, definições e limites de Áreas de Preservação Permanente. Brasília.

CONAMA. Conselho Nacional do Meio Ambiente, 2005. Resolução ${ }^{\circ}$ 357: classificação dos corpos de água e diretrizes ambientais para o seu enquadramento, bem como estabelece as condições e padrões de lançamento de efluentes. Brasília.

DAVIS, J. A.; KEREZSY, A.; NICOL, S. 2016. Springs: Conserving perennial water is critical in arid landscapes. Biological Conservation, n. 211, p. B, p. 30-35.

DUARTE, F. V. et. al. 2004. Projeto Olho D'água-Preservação e Recuperação de Nascentes. Anais do II Congresso Brasileiro de Extensão Universitária, Belo Horizonte, Minas Gerais, Brasil, UFMG. pp. 1-8.

FELIPPE, M. F.; MAGALHÃES JUNIOR, A. P. 2013. Conflitos conceituais sobre nascentes de cursos d'água e propostas de especialistas. Geografias, v. 9, n. 1, p.70-81.

KRUTZ, L, 2005. Reducing herbicide runoff from agricultural fields with vegetative filter strips: a review. Weed Science, v. 53, p. 353-367.

LAINI, A.; BARTOLI, M.; LAMASTRA, L.; CAPRI, E.; BALDERACCHI, M.; TREVISAN, M. 2012. Herbicide contamination and dispersion pattern in lowland springs. Science of the Total Environment, n. 438, p. 312-318.

LEFF, E. 2009. Saber ambiental: sustentabilidade, racionalidade, complexidade, poder. Petrópolis, Rio de Janeiro.

LITTLE, P. E. 2001. Os conflitos socioambientais: um campo de estudo e de ação política, In: A difícil sustentabilidade: política energética e conflitos ambientais. 1 ed. Garamond, Rio de Janeiro. pp. 107-122.

MACHADO, L. C. 2013. O Papel das Nascentes na Sustentabilidade de Assentamentos Rurais. 
Dissertação de Mestrado, Universidade Federal de Pernambuco. Recife, Pernambuco. 125p.

MENDONÇA, M. G. 2000. Políticas e condições ambientais de Uberlândia - MG, no contexto estadual e federal. Dissertação de Mestrado, Universidade Federal de Uberlândia, Uberlândia, Minas Gerais. 84p.

MIRANDA, R. de S. 2011. Os desafios da Organização em Assentamentos Rurais. Revista Verde de Agroecologia e Desenvolvimento Sustentável, v. 6, n. 2, p. 41-48.

MS. Ministério da Saúde. 2011. Portaria n ${ }^{\circ} 2914$ : procedimentos de controle e de vigilância da qualidade da água para consumo humano e seu padrão de potabilidade. Brasília.

OLIVEIRA, C. R. de. 2014. Qualidade da água e conservação de nascentes em assentamento rural na mata pernambucana. Dissertação de Mestrado, Universidade Federal de Pernambuco. Recife, Pernambuco. 141p.

PALIVODA. A. P.; POVALUK, M. 2015. Avaliação do estado de conservação de nascentes localizadas em áreas rurais do município de Itaiópolis, SC. Saúde \& Meio Ambiente: Revista Interdisciplinar, v. 4, n. 1, p. 17-31.

PEREIRA, L. C. 2012. Uso e conservação de nascentes em assentamentos rurais. Dissertação de Mestrado, Universidade Federal de Pernambuco. Recife, Pernambuco. 181p.

PINTO, L. V. A. 2003. Caracterização física da sub-bacia do Ribeirão Santa Cruz, Lavras, MG, e proposta de recuperação de suas nascentes. Dissertação de Mestrado, Universidade Federal de Lavras. Lavras, Minas Gerais. 165p.

PINTO, L. V. A.; BOTELHO, S. A.; DAVIDE, A. C.; FERREIRA, E. 2004. Estudo das nascentes da bacia hidrográfica do Ribeirão Santa Cruz, Lavras, MG. Scientia Florestalis, n. 65, p. 197206.

RESENDE, H. C.; MENDES, D. R.; MENDES, J. E. DAS G.; BERNARDES, W. A. 2009. Diagnóstico e ações de conservação e recuperação para as nascentes do Córrego-feio, Patrocínio, MG. Bioscience Journal, v. 25, n. 5, p. 112-119.

RIBEIRO, A. S. 2014. Estado de conservação das nascentes do alto trecho do Rio Pajeú, Pernambuco, Brasil. Dissertação de Mestrado, Universidade Federal de Pernambuco, Recife, Pernambuco. 202p.

RODRIGUES, R. R.; GANDOLFI, S. 2000. Conceitos, tendências e ações para a recuperação de florestas ciliares. In Matas ciliares: conservação e recuperação. 1 ed. EDUSP; FAPESP, São Paulo. pp. 235-247.

ROSSI, P. M. et. al. 2015. Environmental conditions of boreal springs explained by capture zone characteristics. Journal of Hydrology, v.531, p.3, 992-1002.

SILVA, C. E. M.; Braga, R. A. P. 2010. Conservação de nascentes na adequação ambiental de assentamentos rurais. X Simpósio de Recursos Hídricos do Nordeste, Fortaleza, Ceará, Brasil, ABRH. pp. 1-19.

SILVA, M. de S. et al. 2017. Avaliação da cobertura do solo como indicador de gestão de recursos hídricos: um caso de estudo na sub-bacia do Córrego dos Bois, Minas Gerais. Engenharia Sanitária Ambiental, v. 22. n. 3. p. 445-452.

VALENTE, O. F.; Gomes, M. A. 2011. Conservação de nascentes: produção de água em pequenas bacias hidrográficas, Aprenda Fácil, Minas Gerais. 